\title{
Technical note: Nontargeted detection of adulterated plant proteins in raw milk by UPLC-quadrupole time-of-flight mass spectrometric proteomics combined with chemometrics
}

\author{
Weiying Lu, ${ }^{*}$ Jie Liu, $\dagger^{1}$ Boyan Gao, $\ddagger$ Xiaxia Lv, ${ }^{*}$ and Liangli (Lucy) Yu $\ddagger^{1}$ \\ *Institute of Food and Nutraceutical Science, Department of Food Science and Technology, School of Agriculture and Biology, \\ Shanghai Jiao Tong University, 200240 Shanghai, China \\ †Beijing Advanced Innovation Center for Food Nutrition and Human Health, Beijing Technology and Business University (BTBU), \\ Beijing 100048, China \\ ‡Department of Nutrition and Food Science, University of Maryland, College Park 20742
}

\begin{abstract}
We built and validated a chemometric model to detect possible milk adulteration with plant proteins. Specifically, we extracted proteins in raw milk, treated with tryptic digestion, and obtained peptide fingerprints by UPLC-quadrupole time-of-flight-mass spectrometry with proteomics to differentiate authentic milks from their counterparts adulterated with nonmilk proteins. This approach is able to detect soybean and pea powder-adulterated milks at as low as 1\% (wt/ wt). Additionally, we obtained the characteristic peptide sequences for milk authentication by principal component analysis. The prediction accuracies for milk authentication by partial least-squares-discriminant analysis were greater than $95 \%$. These results indicated that peptide fingerprints with the chemometric analysis could be successfully applied for milk quality control.
\end{abstract} Key words: milk adulteration, nontargeted fingerprinting, UPLC-qTOF-MS, chemometrics

\section{Technical Note}

Milk-related food fraud was ranked second in the food fraud and economic adulteration database in 2012 (Moore et al., 2012). A typical type of fraud is adulteration using inexpensive materials, such as soybean or pea powder, to raise the protein content of milk (Luykx et al., 2007). Alteration of protein composition in milk potentially threatens customers' well-being and food safety (Sanchez-Monge et al., 2004). Consequently, techniques to differentiate authentic milk from adulterated milk with nonmilk proteins is in high demand.

In recent years, various analytical methods, including chromatography, spectroscopy, and enzyme immunoas-

Received January 10, 2017.

Accepted May 15, 2017.

${ }^{1}$ Corresponding authors: Liu_Jie@btbu.edu.cn and lyu5@umd.edu say combined with chemometric techniques, have been investigated in quality control of milk (Cheng et al., 2010; Mecker et al., 2012; Jablonski et al., 2014; Lu et al., 2015). For instance, Jablonski et al. (2014) used UPLC coupled with UV detector to detect soybean and pea proteins in skim milk powder above $3 \%$ (wt/wt). Lu et al. (2015) successfully applied a UPLC AA fingerprinting technique in differentiating milk and nonmilk proteins in our previous study. Near-infrared and Raman spectroscopy combined with principal component analysis (PCA) and partial least-squares-discriminant analysis (PLS-DA) were used to detect possible adulteration in liquid and powdered milk (Botros et al., 2013; Yang et al., 2013; Alves da Rocha et al., 2015; Nieuwoudt et al., 2016). However, these methods often offered little information about the identities of adulterated proteins, which limited the final precision for the identification of adulterated proteins. Mass spectrometric proteomics has been proven reliable in identification of proteins due to its high sensitivity and accuracy (Czerwenka et al., 2007; Luykx et al., 2007; Cordewener et al., 2009; Cunsolo et al., 2011; Nicolaou et al., 2011; Gao et al., 2014; Chen et al., 2016). The frequently used approach is bottom-up MS proteomics, in which peptide fragments are obtained by enzyme digestion (Baldwin, 2004).

Previously, Luykx et al. (2007) demonstrated that authentic milk and counterparts adulterated with numerous soy or pea storage proteins could be identified using liquid chromatography with tandem mass spectrometry in combination with a borate enrichment step. However, uncertainty of the adulterant in actual application will demand a nontargeted detection approach (i.e., an approach that statistically defines what signals should be included in authentic samples), and any samples showing abnormal signals are determined to be not authentic. Unlike a screening approach such as spectroscopy, the MS proteomics-based nontargeted detection model is more challenging because proteomics 
analysis by liquid chromatography-mass spectrometry (LC-MS) is more time-consuming.

Our study aimed to evaluate the suitability of nontargeted UPLC-quadrupole time-of-flight-mass spectrometric (UPLC-qTOF-MS) proteomics model for differentiating authentic and adulterated raw milk. Specifically, differentiation is performed on a relatively large batch of adulterated and unadulterated samples (84 samples) using proteomics and chemometrics without any specific standards to achieve a model with certain statistical confidence (Hiller et al., 2009; Robinson et al., 2011; Gao et al., 2012). In our study, PCA was used to explore the distribution of the data, and PLS-DA was used to construct chemometric models and validate the model automatically without human intervention. We demonstrated that nontargeted peptide fingerprinting is feasible to provide a foundation toward effective quality control of raw milk and its related products, such as infant milk powder.

We collected raw milk samples from local dairy farms in China. We gathered 64 milk samples, including 31 and 33 samples collected in Shandong and Shanghai, China, respectively. The samples were lyophilized using a freeze dryer (Labconco, Kansas City, MO) once transferred to the laboratory and stored at $-20^{\circ} \mathrm{C}$. Two pea proteins and 3 soybean proteins were included as potential adulterants. Pea protein 1 and 2 were from Shuangta Food (Yantai, Shandong, China). Soybean protein 1 was from Gushen Biotech (Dezhou, Shandong, China), soybean protein 2 and 3 were from Yuwang Food (Yucheng, Shandong, China).

Milk powder was reconstituted in water to $20 \mathrm{mg} /$ $\mathrm{mL}$ (20 mg of milk powder per milliliter of solution). Samples were shaken in a water bath at $40^{\circ} \mathrm{C}$ for 30 min to dissolve, and then centrifuged at $3,900 \times g$ for $10 \mathrm{~min}$ at $4^{\circ} \mathrm{C}$. Solution that contained soluble proteins was collected as the stock solution, and the undissolved fats and water-insoluble proteins were discarded. Subsequently, the stock solution was diluted twice with water to make the working solutions. The dilution ratios were chosen separately to reach the protein concentration of $2.0 \pm 0.1 \mathrm{mg} / \mathrm{mL}$, quantitated by the enhanced bicinchoninic acid protein assay kit (Beyotime Biotechnology, Shanghai, China) with a standard curve prepared using a $25 \mathrm{mg} / \mathrm{mL}$ BSA standard solution.

Adulterated milk simulants at 4 different levels were prepared, including 1, 2, 4, and $10 \%$ (wt/wt, weight percentages of nonmilk protein in total milk protein). One milk sample from Shanghai was randomly selected as an authentic milk standard. First, nonmilk protein powders were dissolved and then added to authentic milk at a certain proportion. Both working solutions of milk and foreign proteins were prepared to reach
Table 1. Preparation of adulterated milk

\begin{tabular}{llcc}
\hline Item & Abbreviation & $\begin{array}{c}\text { Nonmilk protein } \\
\text { solvent }(\mathrm{mL})\end{array}$ & $\begin{array}{c}\text { Milk } \\
(\mathrm{mL})\end{array}$ \\
\hline 1\% Soybean milk & $1 \% \mathrm{~S}$ & 0.1 & 9.9 \\
$2 \%$ Soybean milk & $2 \% \mathrm{~S}$ & 0.2 & 9.8 \\
$4 \%$ Soybean milk & $4 \% \mathrm{~S}$ & 0.4 & 9.6 \\
$10 \%$ Soybean milk & $10 \% \mathrm{~S}$ & 1.0 & 9.0 \\
$1 \%$ Pea milk & $1 \% \mathrm{P}$ & 0.1 & 9.9 \\
$2 \%$ Pea milk & $2 \% \mathrm{P}$ & 0.2 & 9.8 \\
$4 \%$ Pea milk & $4 \% \mathrm{P}$ & 0.4 & 9.6 \\
$10 \%$ Pea milk & $10 \% \mathrm{P}$ & 1.0 & 9.0 \\
\hline
\end{tabular}

a final protein concentration of $2.0 \pm 0.1 \mathrm{mg} / \mathrm{mL}$ for further analysis. The preparation of adulterated milk is outlined in Table 1. Specifically, a calculated volume of working solution of nonmilk protein was added to the milk working solution to achieve an expected adulterant level. Adulterated samples were vortexed immediately. Forty adulterated milk samples were prepared.

The samples were treated by trypsin (Sigma-Aldrich, St. Louis, MO) to convert proteins to peptide fragments according to previous tryptic digestion protocols (Zhang et al., 2012, 2014). First, $1 \mathrm{~mL}$ of working solution was added to $1 \mathrm{~mL}$ of $100 \mathrm{mM}$ ammonium bicarbonate (Sigma-Aldrich); the mixtures were then vortexed. Afterward, the disulfide bonds were reduced with $10 \mu \mathrm{L}$ of $1 M$ DL-dithiothreitol (Sigma-Aldrich) at $50^{\circ} \mathrm{C}$ in a water bath for $30 \mathrm{~min}$. Alkylation for reduced cysteine side chains was carried out with $30 \mu \mathrm{L}$ of 1 $M$ iodoacetamide (Sigma-Aldrich) in the dark for 30 min. Subsequently, $20 \mu \mathrm{L}$ of $2 \mathrm{mg} / \mathrm{mL}$ trypsin solutions were added and the mixtures were incubated at $37^{\circ} \mathrm{C}$ for $12 \mathrm{~h}$. Tryptic hydrolysates were heated at $85^{\circ} \mathrm{C}$ for $10 \mathrm{~min}$ to terminate digestion. The digested mixtures were centrifuged at $16,110 \times g$ for $15 \mathrm{~min}$ at $4^{\circ} \mathrm{C}$. The supernatants were stored at $-20^{\circ} \mathrm{C}$ before UPLC-MS analysis. All samples were prepared in duplicate.

The UPLC-MS analyses were performed by a Waters Acquity H-class UPLC system coupled to a Xevo G2 quadrupole time-of-flight mass spectrometer (Waters, Milford, MA). A UPLC BEH C18 column (2.1 mm i.d. $\times 100 \mathrm{~mm}, 1.7 \mu \mathrm{m}$, Waters) with a VanGuard BEH C18 precolumn (2.1 mm i.d. $\times 5 \mathrm{~mm}, 1.7 \mu \mathrm{m}$, Waters $)$ was used for separation. The column temperature was $30^{\circ} \mathrm{C}$ and the sample temperature was $10^{\circ} \mathrm{C}$. The injection volume was $5.0 \mu \mathrm{L}$. The $0.1 \%$ (vol/vol) formic acid (Sigma-Aldrich) in Milli-Q deionized water (EMD Millipore, Darmstadt, Germany) and 0.1\% (vol/vol) formic acid in acetonitrile (HPLC-grade, Merck, Darmstadt, Germany) were used as mobile phases. The total run time for each injection was 78 min. The long run time ensured clear separation of peptides. The linear elution gradient program is listed in Table 2. A blank 


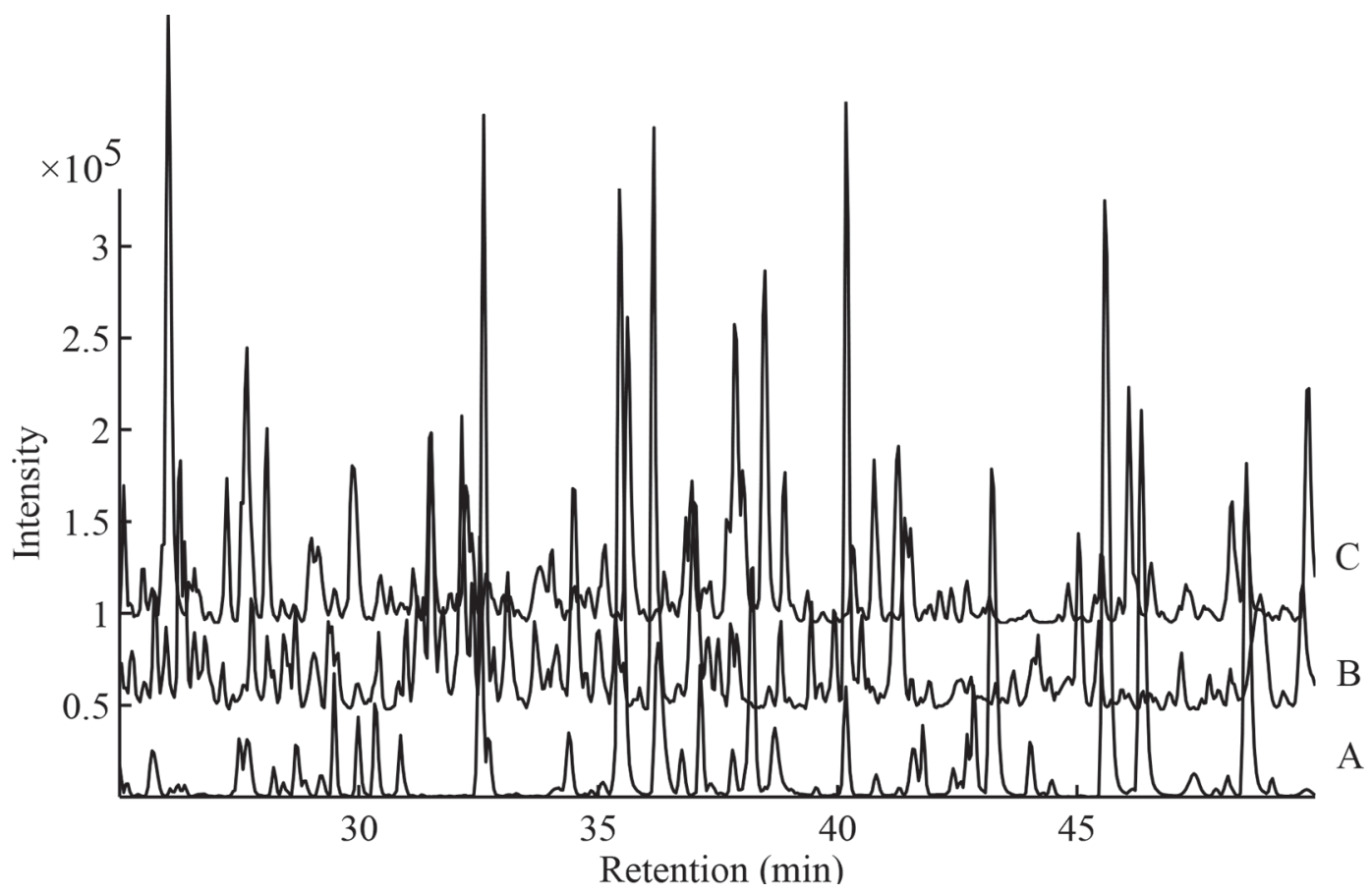

Figure 1. Base peak intensity chromatograms of peptides generated by milk and different nonmilk proteins: (A) milk, (B) soybean, (C) pea.

run (acetonitrile, HPLC grade, Merck) was injected between every 10 injections.

The mass spectrometer was operated with an electrospray ionization source under the positive ion mode. The capillary voltage was $3.0 \mathrm{kV}$; the sampling cone voltage was $40 \mathrm{~V}$. The source temperature was $120^{\circ} \mathrm{C}$ and the desolvation temperature was $450^{\circ} \mathrm{C}$. The cone gas flow was $50 \mathrm{~L} / \mathrm{h}$ and the desolvation gas flow was $600 \mathrm{~L} / \mathrm{h}$. Two channels of MS signals were collected. Channel 1 was recorded at $6.0 \mathrm{eV}$ of collision energy and channel 2 was recorded between 20 to $50 \mathrm{eV}$. The scanning speed was $0.3 \mathrm{~s} / \mathrm{scan}$; the mass spectra between 50 and $1,800 \mathrm{~m} / z$ were recorded.

Base peak intensity chromatograms of peptides generated by milk and different nonmilk proteins are given

Table 2. Gradient elution program for $\mathrm{UPLC}^{1}$

\begin{tabular}{lccc}
\hline Time $(\mathrm{min})$ & Flow $(\mathrm{mL} / \mathrm{min})$ & A $(\%)$ & B $(\%)$ \\
\hline 0.0 & 0.4 & 98 & 2 \\
4.9 & 0.4 & 98 & 2 \\
5.0 & 0.2 & 98 & 2 \\
65.0 & 0.2 & 60 & 40 \\
67.0 & 0.4 & 15 & 85 \\
75.0 & 0.4 & 0 & 100 \\
76.0 & 0.4 & 98 & 2 \\
78.0 & 0.4 & 98 & 2 \\
\hline
\end{tabular}

${ }^{1} \mathrm{~A}=0.1 \%(\mathrm{vol} / \mathrm{vol})$ formic acid in deionized water; $\mathrm{B}=0.1 \%(\mathrm{vol} / \mathrm{vol})$ formic acid in acetonitrile. in Figure 1. Base peak intensity chromatograms were similar to TIC chromatograms, except they contained only the intensity of the most intense mass spectral peak at each chromatogram scan, which greatly avoids interferences of the baseline noise (Murray et al., 2013). The elution pattern of plant peptides differs greatly from that of milk during 25 to 27,27 to 32,36 to 40 , and 41 to $45 \mathrm{~min}$ due to the dissimilar polarity of peptides.

The UPLC-MS spectra were analyzed using ProteinLynx Global Server (PLGS; version 3.0, Waters) to identify proteins in the samples. The PLGS parameters were lock mass window at $0.25 \mathrm{Da}$, low-energy threshold at 25 counts, the elevated energy threshold was 10 counts, the intensity threshold was 750 counts, and the peptide tolerance was $10 \mu \mathrm{g} / \mathrm{mL}$. Matched protein fragments and their corresponding intensities were exported to a spreadsheet file. Although protein identification provides further information of the nonmilk proteins, it is not essential for a nontargeted adulteration detection. The identification of abnormal samples can be performed solely on peptide fragments or raw spectral data when handling unknown plant protein adulterants without sequencing data.

We identified 267 proteins in adulterated milk matched by PLGS. After manual comparison, the identities of 26 major relevant proteins were revealed (Table 3). Six major bovine milk proteins $\left(\alpha-\mathrm{LA}, \alpha_{\mathrm{S}^{-}}\right.$, 
$\alpha_{\mathrm{S}^{-}}$and $\beta-\mathrm{CN}, \beta-\mathrm{LG}$, and glycosylation-dependent cell adhesion molecule-1) were detected in both authentic and adulterated milk samples. Eleven soybean and 9 pea proteins in adulterated milk at the $10 \%$ adulterant level were identified, respectively. The identified soybean proteins included trypsin inhibitor, glycinin, conglycinin, and albumin, and the identified pea proteins included provicilin, vicilin, legumin, and convicilin. The numbers of identified proteins were less than the work by Luykx et al. (2007), in which a borate enrichment step before liquid chromatography with tandem mass spectrometry measurement could identify 12 soybean and 11 pea proteins in adulterated milk at $5 \%$ (wt/wt). However, only 3 bovine milk proteins were detected at the same time. Moreover, the detection limits of the UPLC method for foreign proteins in skim milk powder were above $3 \%$ (wt/wt, percentages over total weight) by Jablonski et al. (2014). In comparison, soybean protein ( $\beta$-conglycinin, $\alpha$ and $\beta$ subunit) and pea protein (provicilin type $\mathrm{B}$ and vicilin) could be detected at $1 \%$ (weight percentages of nonmilk protein over milk protein) in the current study, exemplifying the better sensitivity of our approach.

All data were then processed using MATLAB R2013b software package (The MathWorks, Natick, MA) for chemometrics processing. The peptide intensities of the precursor ions were used for chemometrics modeling. The intensities were combined when peptides had different retention times within the same sequence. The autoscaling preprocessing was used before data modeling. Both PCA and PLS-DA were performed using in-house MATLAB programs. The fingerprint data set consisted of 169 objects with 1,799 variables (peptide sequences). These peptide sequences contained the peptides generated by milk and nonmilk proteins.

The data set was examined for its overall distribution using all available peptide information with exploratory data analysis by PCA. The principal component scores and loading plots for authentic and adulterated milks using the targeted method are displayed in Figure 2. The first 2 principal component scores are plotted in Figure 2A. The adulterated milk samples formed 2 clusters away from the authentic milk samples. Three separated clusters suggested the authentic and adulterated milks were clearly differentiated from each other. Milks mixed with different types of plant proteins behaved differently in PCA, which could be attributed to different mass fingerprints of plant protein (Cordewener et al., 2009). The loading plot yielded similar presentation of point distribution, except each point corresponded

Table 3. Identified proteins in adulterated milk ${ }^{1}$

\begin{tabular}{|c|c|c|c|c|c|c|}
\hline P00711 & Bos taurus & $\alpha-\mathrm{LA}$ & 16,247 & 38.73 & 7,196 & All \\
\hline P02663 & Bos taurus & $\alpha_{\mathrm{S} 2^{-}} \mathrm{CN}$ & 26,019 & 23.87 & 2,917 & All \\
\hline P02666 & Bos taurus & $\beta-\mathrm{CN}$ & 25,107 & 21.88 & 2,245 & All \\
\hline P02754 & Bos taurus & $\beta-\mathrm{LG}$ & 19,883 & 79.21 & 18,920 & All \\
\hline P80195 & Bos taurus & GlyCAM-1 & 17,152 & 23.53 & 1,737 & All \\
\hline P02858 & Glycine $\max$ & Glycinin G4 & 63,587 & 31.32 & 625 & $10 \% \mathrm{~S} 1 ; 10 \% \mathrm{~S} 2 ; 10 \% \mathrm{~S} 3$ \\
\hline P04347 & Glycine $\max$ & Glycinin & 57,956 & 22.48 & 255 & $10 \% \mathrm{~S} 3$ \\
\hline P04405 & Glycine $\max$ & Glycinin G2 & 54,931 & 31.13 & 1,437 & $4 \%-, 10 \% \mathrm{~S} 1 ; 4 \%-, 10 \% \mathrm{~S} 2 ; 4 \%-, 10 \% \mathrm{~S} 3$ \\
\hline P04776 & Glycine $\max$ & Glycinin G1 & 55,706 & 36.57 & 992 & $4 \%-, 10 \% \mathrm{~S} 1 ; 4 \%-, 10 \% \mathrm{~S} 2 ; 4 \%-, 10 \% \mathrm{~S} 3$ \\
\hline P11827 & Glycine $\max$ & $\beta$-Conglycinin, $\alpha^{\prime}$ subunit & 74,325 & 36.15 & 770 & $4 \%-, 10 \% \mathrm{~S} 1 ; 10 \% \mathrm{~S} 2 ; 10 \% \mathrm{~S} 3$ \\
\hline P11828 & Glycine $\max$ & Glycinin G3 & 54,242 & 5.82 & 388 & $10 \% \mathrm{~S} 1 ; 10 \% \mathrm{~S} 2 ; 4 \%-, 10 \% \mathrm{~S} 3$ \\
\hline P13916 & Glycine $\max$ & $\beta$-Conglycinin, $\alpha$ subunit & 70,293 & 40.66 & 2,162 & $1 \%-, 2 \%_{-}, 4 \%-, 10 \% \mathrm{~S} 1 ; 4 \%-, 10 \% \mathrm{~S} 2 ; 4 \%-, 10 \% \mathrm{~S} 3$ \\
\hline $\mathrm{P} 02857$ & Pisum sativum & Legumin A & 58,805 & 17.21 & 230 & $10 \% \mathrm{P} 1$ \\
\hline $\mathrm{P} 13915$ & Pisum sativum & Convicilin & 66,990 & 19.26 & 689 & $4 \%-, 10 \% \mathrm{P} 1 ; 4 \%^{-}, 10 \% \mathrm{P} 2$ \\
\hline P13918 & Pisum sativum & Vicilin & 52,231 & 44.01 & 2,579 & $2 \%_{-}^{-, 4 \%-}, 10 \% \mathrm{P} 1 ; 1 \%-, 4 \%-, 10 \% \mathrm{P} 2$ \\
\hline P13919 & Pisum sativum & Convicilin & 46,396 & 28.24 & 435 & $10 \% \mathrm{P} 1$ \\
\hline P14594 & Pisum sativum & Legumin B & 38,990 & 21.89 & 1,153 & $4 \%-, 10 \% \mathrm{P} 1 ; 4 \%-, 10 \% \mathrm{P} 2$ \\
\hline P15838 & Pisum sativum & Legumin A2 & 59,270 & 21.73 & 424 & $10 \% \mathrm{P} 1 ; 4 \%-, 10 \% \mathrm{P} 2$ \\
\hline
\end{tabular}

${ }^{1} \mathrm{ID}=$ protein accession number; coverage = percent protein sequence coverage; GlyCAM-1 = glycosylation-dependent cell adhesion molecule 1. $\mathrm{All}=$ detected in all samples; $\mathrm{X} \% \mathrm{Y}$ means sample adulterated with nonmilk protein $\mathrm{Y}$ at $\mathrm{X} \%$ (wt/wt); S1, S2, and S3 were 3 soybean proteins. $\mathrm{P} 1$ and $\mathrm{P} 2$ were 2 pea proteins. 
to a peptide fragment in the sample. Specifically, some characteristic peptide sequences for differentiating authentic and adulterated milks could be easily identified from the loading plot (Figure 2B). For instance, LQES-
VIVEISK, FYLAGNQEQEFLK, SQSDNFEYVSFK, and QIVTVEGGLSVISPK had high values in milks adulterated with pea proteins according to the loading of the first principal component. These peptide
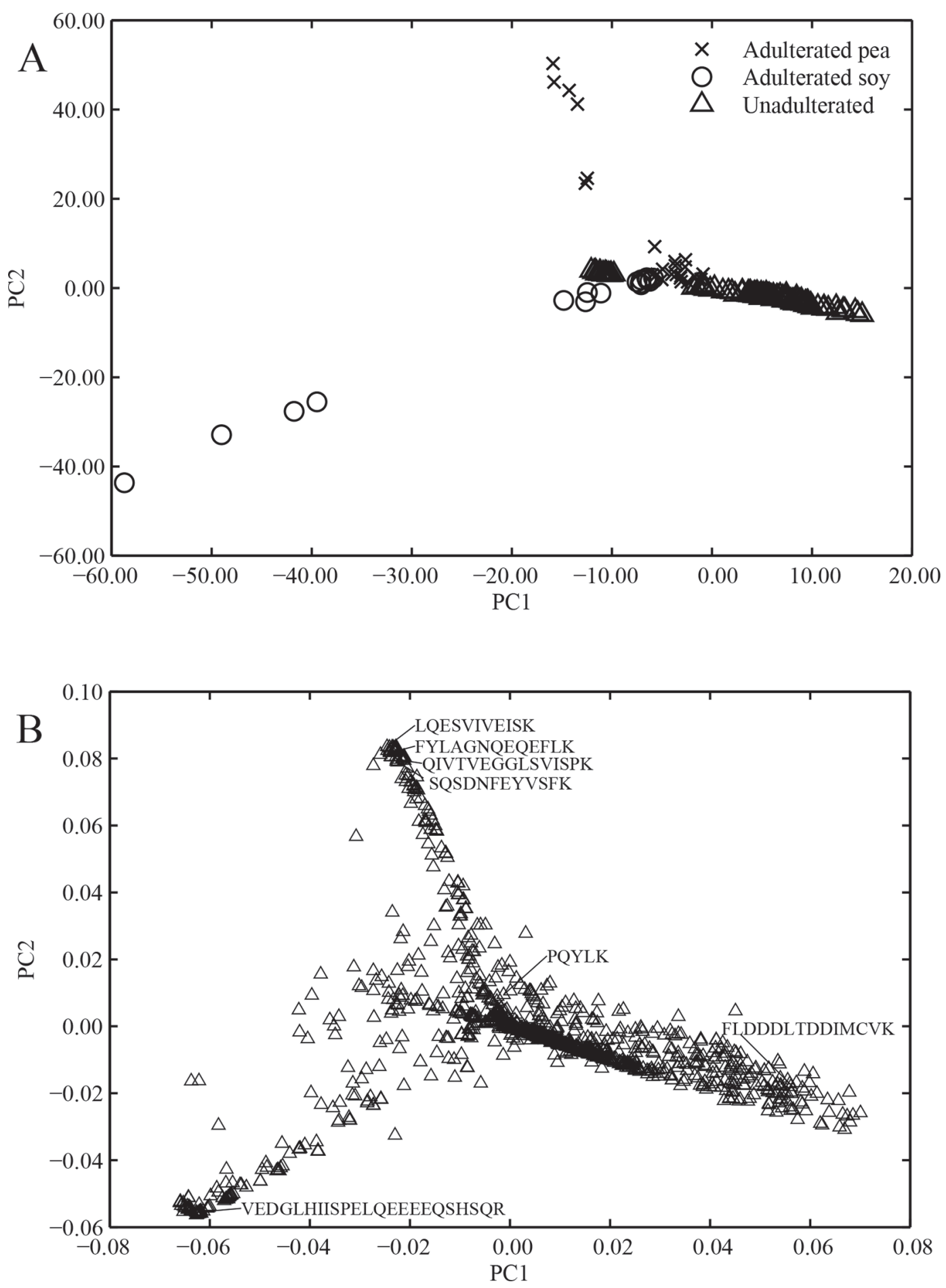

Figure 2. Principal component (PC) analysis scores (A) and loading (B) plots for authentic and adulterated milk. The representative peptides are labeled. 
sequence existed in glycinin G2 (P04405), glycinin G1 (P04776), $\beta$-conglycinin, $\alpha^{\prime}$ subunit (P11827), glycinin G3 (P11828), and $\beta$-conglycinin, $\alpha$ subunit (P13916), as shown in Table 3. According to the second principal component, VEDGLHIISPELQEEEEQSHSQR was typically high in adulterated milk with soybean proteins, and legumin B (P14594) contained this peptide sequence. In addition, PQYLK and FLDDDLTDDIMCVK accounted for the main part on both principal components in milk, which existed in $\alpha_{\mathrm{S}_{2}} \mathrm{CN}$ (P02663) and $\alpha$-LA (P00711). This result was consistent with the previous PLGS analysis, which showed that all corresponding proteins could be identified in most adulterated milks (Table 3). Our finding is also in agreement with the previous study by Luykx et al. (2007), in which glycinin, $\beta$-conglycinin (soybean), and legumin (pea) could be identified in adulterated milks with plant proteins.

The PLS-DA was applied afterward as a fully automated multivariate classification method, and the model was validated by an independent set of samples. Specifically, the fingerprints were divided into a training set ( $75 \%$ samples) and a test set ( $25 \%$ samples) using the Kennard-Stone algorithm (Kennard and Stone, 1969). The bootstrapped Latin partition of 10 bootstraps and 5-fold Latin partition was used to select suitable numbers of latent variables, following the method reported by $\mathrm{Lu}$ et al. (2014). The prediction accuracies were $100 \%$ for both training and test set (latent variables $=3$ ), respectively. This finding was consistent with the result of PCA, indicating peptide fingerprint combined with chemometrics successfully differentiated milk and adulterated milk.

In summary, we successfully differentiated authentic and adulterated milk by nontargeted UPLC-MS peptide fingerprints combined with chemometrics analyses. We detected soybean protein ( $\beta$-conglycinin, $\alpha$ and $\beta$ subunit) and pea protein (provicilin type B and vicilin) at the $1 \%$ adulteration level (percentage of foreign protein in milk protein). In an independent model validation using PLS-DA, all samples in the test set were correctly classified. The results indicated that UPLC-qTOF-MS peptide fingerprints with chemometrics were able to successfully differentiate authentic and adulterated milk. These findings may assist the quality control of raw milk and its related products in the future.

\section{ACKNOWLEDGMENTS}

This work was supported by a special fund for Agroscientific Research in the Public Interest from the Ministry of Agriculture of China (Beijing, China; Grant No. 201203069); National Natural Science Foundation of China (Beijing, China; Grant No. 31501553; 31501479);
National High Technology Research and Development Program of China from the Ministry of Science and Technology of China (Beijing, China; Grant No. 2013AA102202; 2013AA102207); and research funds from Beijing Advanced Innovation Center for Food Nutrition and Human Health at Beijing Technology and Business University (BTBU) in Beijing, China and Nestec Ltd. (Vevey, Switzerland).

\section{REFERENCES}

Alves da Rocha, R., I. M. Paiva, V. Anjos, M. A. M. Furtado, and M. J. V. Bell. 2015. Quantification of whey in fluid milk using confocal Raman microscopy and artificial neural network. J. Dairy Sci. 98:3559-3567. https://doi.org/10.3168/jds.2014-8548.

Baldwin, M. A. 2004. Protein identification by mass spectrometry: Issues to be considered. Mol. Cell. Proteomics 3:1-9. https://doi .org/10.1074/mcp.R300012-MCP200.

Botros, L. L., J. Jablonski, C. Chang, M. M. Bergana, P. Wehling, J. M. Harnly, G. Downey, P. Harrington, A. R. Potts, and J. C. Moore. 2013. Exploring authentic skim and nonfat dry milk powder variance for the development of nontargeted adulterant detection methods using near-infrared spectroscopy and chemometrics. J. Agric. Food Chem. 61:9810-9818. https://doi.org/10.1021/ jf4023433.

Chen, Q., X. Ke, J. S. Zhang, S. Y. Lai, F. Fang, W. M. Mo, and Y. P. Ren. 2016. Proteomics method to quantify the percentage of cow, goat, and sheep milks in raw materials for dairy products. J. Dairy Sci. 99:9483-9492. https://doi.org/10.3168/jds.2015-10739.

Cheng, Y., Y. Dong, J. Wu, X. Yang, H. Bai, H. Zheng, D. Ren, Y. Zou, and M. Li. 2010. Screening melamine adulterant in milk powder with laser Raman spectrometry. J. Food Compos. Anal. 23:199-202. https://doi.org/10.1016/j.jfca.2009.08.006.

Cordewener, J. H., D. M. Luykx, R. Frankhuizen, M. G. Bremer, H. Hooijerink, and A. H. America. 2009. Untargeted LC-Q-TOF mass spectrometry method for the detection of adulterations in skimmed-milk powder. J. Sep. Sci. 32:1216-1223. https://doi.org/ $10.1002 /$ jssc. 200800568 .

Cunsolo, V., V. Muccilli, R. Saletti, and S. Foti. 2011. Review: Applications of mass spectrometry techniques in the investigation of milk proteome. Eur. J. Mass Spectrom. (Chichester, Eng.) 17:305320. https://doi.org/10.1255/ejms.1147.

Czerwenka, C., I. Maier, N. Potocnik, F. Pittner, W. Lindner, and A. Chem. 2007. Absolute quantitation of beta-lactoglobulin by protein liquid chromatography-mass spectrometry and its application to different milk products. Anal. Chem. 79:5165-5172. https://doi .org/10.1021/ac062367d.

Gao, B., Y. Lu, F. Qin, P. Chen, H. Shi, D. Charles, and L. Yu. 2012. Differentiating organic from conventional peppermints using chromatographic and flow injection mass spectrometric (FIMS) fingerprints. J. Agric. Food Chem. 60:11987-11994. https://doi.org/10 $.1021 /$ jf303415d.

Gao, B., F. Qin, T. Ding, Y. Chen, W. Lu, and L. L. Yu. 2014. Differentiating organically and conventionally grown oregano using ultraperformance liquid chromatography mass spectrometry (UPLC-MS), headspace gas chromatography with flame ionization detection (headspace-GC-FID), and flow injection mass spectrum (FIMS) fingerprints combined with multivariate data analysis. J. Agric. Food Chem. 62:8075-8084. https://doi.org/10.1021/ jf502419y.

Hiller, K., J. Hangebrauk, C. Jäger, J. Spura, K. Schreiber, D. Schomburg, and A. Chem. 2009. Metabolitedetector: Comprehensive analysis tool for targeted and nontargeted GC/MS based metabolome analysis. Anal. Chem. 81:3429-3439. https://doi.org/10 $.1021 / \mathrm{ac} 802689 \mathrm{c}$.

Jablonski, J. E., J. C. Moore, and J. M. Harnly. 2014. Nontargeted detection of adulteration of skim milk powder with foreign proteins 
using UHPLC-UV. J. Agric. Food Chem. 62:5198-5206. https:// doi.org/10.1021/jf404924x.

Kennard, R. W., and L. A. Stone. 1969. Computer aided design of experiments. Technometrics 11:137-148.

Lu, W., Q. Jiang, H. Shi, Y. Niu, B. Gao, and L. L. Yu. 2014. Partial least-squares-discriminant analysis differentiating Chinese wolfberries by UPLC-MS and flow injection mass spectrometric (FIMS) fingerprints. J. Agric. Food Chem. 62:9073-9080. https://doi.org/ 10.1021/jf502156n.

Lu, W., X. Lv, B. Gao, H. Shi, and L. L. Yu. 2015. Differentiating milk and non-milk proteins by UPLC amino acid fingerprints combined with chemometric data analysis techniques. J. Agric. Food Chem. 63:3996-4002. https://doi.org/10.1021/acs.jafc.5b00702.

Luykx, D. M., J. H. Cordewener, P. Ferranti, R. Frankhuizen, M. G. Bremer, H. Hooijerink, and A. H. America. 2007. Identification of plant proteins in adulterated skimmed milk powder by high-performance liquid chromatography - mass spectrometry. J. Chromatogr. A 1164:189-197. https://doi.org/10.1016/j.chroma .2007.07.017.

Mecker, L. C. K. M. Tyner, J. F. Kauffman, S. Arzhantsev, D. J. Mans, and C. M. Gryniewicz-Ruzicka. 2012. Selective melamine detection in multiple sample matrices with a portable Raman instrument using surface enhanced Raman spectroscopy-active gold nanoparticles. Anal. Chim. Acta 733:48-55. https://doi.org/10 .1016/j.aca.2012.05.001

Moore, J. C., J. Spink, and M. Lipp. 2012. Development and application of a database of food ingredient fraud and economically motivated adulteration from 1980 to 2010. J. Food Sci. 77:R118-R126. https://doi.org/10.1111/j.1750-3841.2012.02657.x.

Murray, K. K., K. Boyd Robert, N. Eberlin Marcos, G. J. Langley, L. Li, and Y. Naito. 2013. Definitions of terms relating to mass spectrometry (IUPAC recommendations 2013). Pure Appl. Chem. 35:20-30. https://doi.org/10.1351/PAC-REC-06-04-06.

Nicolaou, N., Y. Xu, and R. Goodacre. 2011. MALDI-MS and multivariate analysis for the detection and quantification of different milk species. Anal. Bioanal. Chem. 399:3491-3502. https://doi .org/10.1007/s00216-011-4728-6.

Nieuwoudt, M. K., S. E. Holroyd, C. M. McGoverin, M. C. Simpson, and D. E. Williams. 2016. Rapid, sensitive, and reproducible screening of liquid milk for adulterants using a portable Raman spectrometer and a simple, optimized sample well. J. Dairy Sci 99:7821-7831. https://doi.org/10.3168/jds.2016-11100.

Robinson, A. L., P. K. Boss, H. Heymann, P. S. Solomon, and R. D. Trengove. 2011. Development of a sensitive non-targeted method for characterizing the wine volatile profile using headspace solidphase microextraction comprehensive two-dimensional gas chromatography time-of-flight mass spectrometry. J. Chromatogr. A 1218:504-517. https://doi.org/10.1016/j.chroma.2010.11.008.

Sanchez-Monge, R., G. Lopez-Torrejon, C. Y. Pascual, J. Varela, M. Martin-Esteban, and G. Salcedo. 2004. Vicilin and convicilin are potential major allergens from pea. Clin. Exp. Allergy 34:17471753. https://doi.org/10.1111/j.1365-2222.2004.02085.x.

Yang, R. J., R. Liu, K. Xu, and Y. R. Yang. 2013. Discrimination of adulterated milk using NPLS-DA combined with two-dimensional correlation near-infrared spectroscopy. Acta Photonica Sinica $42: 580-585$

Zhang, J., S. Lai, Z. Cai, C. Qi, B. Huang, and Y. Ren. 2014. Determination of bovine lactoferrin in dairy products by ultra-high performance liquid chromatography-tandem mass spectrometry based on tryptic signature peptides employing an isotope-labeled winged peptide as internal standard. Anal. Chim. Acta 829:33-39. https://doi.org/10.1016/j.aca.2014.04.025.

Zhang, J., S. Lai, Y. Zhang, B. Huang, D. Li, and Y. Ren. 2012. Multiple reaction monitoring-based determination of bovine $\alpha$-lactalbumin in infant formulas and whey protein concentrates by ultra-high performance liquid chromatography-tandem mass spectrometry using tryptic signature peptides and synthetic peptide standards. Anal. Chim. Acta 727:47-53. https://doi.org/10 $.1016 /$ j.aca.2012.03.034 